\title{
Peer Learning Amongst Students of Higher Technical Teachers' Training College (HTTTC) of the University of Buea in Kumba, Cameroon
}

\author{
Ngemunang Agnes Ngale Lyonga ${ }^{1}$ \\ ${ }^{1}$ Department of Science of Education, Higher Technical Teachers' Training College (HTTTC) of the University of \\ Buea, Cameroon \\ Correspondence: Ngemunang Agnes Ngale Lyonga, Department of Science of Education, Higher Technical \\ Teachers' Training College (HTTTC), University of Buea, P.O. Box 63, Buea, South West Region, CAMEROON.
}

Received: February 16, 2018

Accepted: April 10, 2018

Online Published: April 11, 2018

doi:10.5430/ijhe.v7n2p216

URL: https://doi.org/10.5430/ijhe.v7n2p216

\begin{abstract}
This paper examines the use of peer learning in students' success at the Higher Technical Teachers' Training College in Kumba, Cameroon. The study uses a quantitative descriptive data to determine the effectiveness of peer learning amongst students through the impact of study groups and peer tutoring on students' achievement. The study employed the descriptive survey design. Participants of the study were made up of 234 students drawn from both the first and second cycles of the 14 departments of the Technical Teachers' Training College (HTTTC), Kumba. The study sought to find out the effects of study groups and peer tutoring on students' achievement at HTTTC, Kumba. A structured questionnaire was used as the instrument for data collection. The data collected was analyzed descriptively using frequencies and percentages computed with the help of the SPSS V.20.0. Evidence from students' responses indicated that the importance of studying in groups with classmates and peer tutoring by other students in the success of their end-of-semester and final examinations cannot be overemphasized. By providing these learning environments in schools, students are able to form a cohesive group where they can express their ideas and help each other succeed. Based on the study findings, it is recommended that students who are more knowledgeable and have a good mastery of the subject or the concepts taught be paired by the teacher with other students for group work, class discussions and more purposeful structured learning. Teachers should also take advantage of the peer tutoring technique to encourage student-teachers to work in small mixed ability groups that will allow everyone whether fast or slow to share their ideas and build knowledge as well as interpersonal skills in the training process.
\end{abstract}

Keywords: peer learning, peer tutoring, group learning, academic achievement, higher technical teachers' training colleges

\section{Introduction}

\subsection{Overview}

There is a vast interest today in understanding how learning in general and academic learning in particular can be improved. It is obvious that the process of learning should focus more on improving the achievement of the learner instead of focusing on the acquisition of certificates which to an extent is not an indication of knowledge acquired. Interested in improving students' success, Oneneto \& Onyibor (2002) stated that poor academic achievement in many schools in Africa queries the methodology of instruction, and therefore called for an in depth investigation with the view of establishing the relationship between instructional methods and students' achievement. Poor academic performances may exist because of many factors and sometimes the method of teaching and learning may be one of the factors. It should be recalled that teaching is an essential aspect of learning and good teaching with the right methods leads to better understanding as well as mastery of subject matter and eventually high academic achievement. Educators, teachers, and trainers are challenged to seek for innovative teaching strategies and interventions that would enhance and enrich academic achievement of students (Oneneto \& Onyibor, 2002; Campit, Cayabyab, \& Galas, 2015).

Goodlad (1984) reported that most classroom time is spent in "teacher talk", with only $1 \%$ of the time used for reasoning or expressing an opinion by students. Being aware of the limitations of teachers' centered methods in Cameroon educational system today (Titanji, 2013), peer learning which is increasingly being used in university and 
organizational settings (Magin \& Churches, 1995; Jackson \& Bruegmann, 2009; Andrews \& Manning, 2015) is also frequently used by students in higher technical teachers' training colleges in Cameroon. Given the problem of limited time in the training of student-teachers to acquire both skills in teaching and competencies in specific specialties areas, many teachers in the training colleges in Cameroon also encouraged peer learning in and out of classrooms.

If assessed, the use of peer learning strategies by students of higher technical teachers' training colleges may have the potential of improving practice in acquiring knowledge, competences in specialized areas, enhancing teaching skills and enriching their self esteem. For example, at the beginning of classes many newly admitted students especially, French-speaking students, are not very comfortable with English which is the language of instruction for their training. The English language limitations of the Francophone students make it difficult for some to follow-up lectures and some shy away from participating during lectures and in other in-class learning activities. As a result of the deficiency in the language of instruction demonstrated by most French-speaking students, some teachers in HTTTC, Kumba are obliged to use diverse instructional methods that enable students to study together; thus, encouraging collaborative group tasks amongst students instead of individual learning activities.

Following these observations, the researcher decided to use the idea of students learning with each other in groups (with their peers) and students teaching each other or other students (Campit, Cayabyab, \& Galas, 2015; Mustafa, 2017) in the form of peer learning in order to find out the effectiveness or benefits of peer learning amongst students in Higher Technical Teachers' Training College (HTTTC), Kumba. Without empirical evidence to support the effectiveness and benefits of peer learning methods in HTTTC, Kumba, such group method of learning is likely to be ignored as a potential instructional methodology for improving students' achievement in higher technical teachers' training colleges in Cameroon where students are admitted from different educational, cultural, and linguistics backgrounds.

Similar to Mustafa's (2017) and Miao's et al., (2017) studies with students from different cultural and linguistics backgrounds in Saudi universities and Chinese students in Australian universities, HTTTC, Kumba admits students with different educational and linguistics cultures within Cameroon to be trained as technical education teachers. In this light therefore, the objective of this study was to determine the importance of peer learning amongst students of HTTTC, with different educational and linguistics culture. While many studies have been done on the effectiveness and benefits of peer learning and peer tutoring (Garcia, Morales, \& Rivera, 2014; Campit, Cayabyab, \& Galas, 2015; Mustafa, 2017; Miao, Henderson, \& Supple, 2017) and other collaborative group learning strategies amongst students (Gillies, 2004, 2006, 2008, 2016; Ling, 2015), this study looks for the importance of peer learning as a learning strategy amongst students studying at higher technical teachers' training colleges which accommodate students from different educational, cultural, and linguistics backgrounds such as the Higher Technical Teachers' Training College (HTTTC) Kumba, Cameroon.

\subsection{The Concepts of Peer Learning}

Peer learning is an approach to group work that minimizes the occurrence of unpleasant situations and maximizes learning experiences with satisfaction that result from working on a high-performance team. As compared to students taught traditionally (with instructor-centered lectures, individual assignments, and competitive grading), the academic advantages of peer learning and students taught using collaboratively group methods are many (Comfort \& McMahon, 2014; Mustafa, 2017, Miao, Henderson, \& Supple, 2017). These advantages include high academic achievement through greater persistence from admission through retention to graduation; better high-level reasoning and critical thinking skills; deeper understanding of learned material; greater time on task and less disruptive behavior; lower levels of anxiety and stress; greater intrinsic motivation to learn and achieve; greater ability to view situations from others' perspectives; more positive and supportive relationships with peers; more positive attitudes toward subject areas; and higher self-esteem (Gillies, 2004, 2006, 2008, 2016; Felder \& Brent, 2007; Comfort \& McMahon, 2014; Ling, 2015).

Without denying the importance of traditional lectures, many researchers (Asher, 1986; Conwel, Piel \& Coobs, 1988; Gallien, 1988; Brown, Collins, \& Duguid, 1989; Johnson \& Johnson, 1985; 1991; Hartman, 1997; Yager, 2000) started leaning towards the assumption that peer learning does not help the in-depth understanding of the concepts. This assumption has resulted in more emphasis on teaching through diverse methods in order to improve learning and understanding. One of such diverse learning strategy is peer learning, which assumes that team effort of students towards a single goal of learning a particular aspect results in more understanding than solo efforts (Dunn, 2001).

The peer learning method has many features for improving the teaching-learning process, and an increasing number of teachers are recognizing its value and also assigning collaborative work to their students (Comfort \& McMahon, 2014; Campit, Cayabyab, \& Galas, 2015; Mustafa, 2017). Small group work, used both in and out of class, can be an 
important tool to lectures, helping students master concepts and apply them to situations calling for complex applications of critical thinking skills (Gillies, 2004, 2006, 2008, 2016; Jackson \& Bruegmann, 2009). For example, LaFleur (2010) investigates peer learning and its influence on students' achievement and confidence in fraction and the role of the teacher in the classroom when students are already into groups. The researcher found that peer learning has a good effect on his students' achievement and also his students were more confident when doing fraction and his role as a teacher seemed to be just a guide. Thus, students working together towards a common goal enjoy the feeling of helping one another to be successful, and the longer the groups worked together, the more beneficial the group work seems to improve their knowledge.

Students working collaboratively in study groups often enjoy the experience and believe that their classmates or peers like them. As presented in the study of Bernero (2000), some students who struggled with mathematics continued to struggle and became frustrated with individual work, but improved both academically and in self-confidence (thus leading to social improvement) when it came to group work. Tella (2013) also investigated the effect of explicit and peer tutoring instructional strategies in pupils' ability and gender in learning mathematics. This study was done with eight primary schools and he found that pupils' ability and gender were found not to have a significant effect on achievement in mathematics and attitude toward the subject. The belief that they are accepted by others also allowed the students to believe that they are more academically successful. Using mathematics again as a subject area, Garcia, Morales, \& Rivera (2014) described a highly successful peer tutoring program that resulted in a significant improvement in success rates in mathematics placement examination of Engineering students.

Using a different subject area, Amaka (2013) conducted a study to find out the effect of peer tutoring instructional method on academic achievement in Home Economics among secondary school students in Dunukofia, Anambra State, Nigeria. All senior secondary school students in the local government area constituted the population of a quasi-experimental design study. Four secondary schools out of eight secondary schools were randomly selected, and all the 145 students offering Home Economics in these four schools were selected and assigned to experimental and control groups. Data on student's achievement was collected using Home Economics achievement test. The results indicated that students taught Home Economics using peer tutoring instructional methods achieved higher than those taught using lecture method. She recommended in her study that peer tutoring should be used in teaching Home Economics in secondary schools to enhance students' achievement.

At the university level, Miao, Henderson, \& Supple (2017) carried out an on-line pre-departure peer learning study for Chinese students going to Australian universities. The researchers explored ways in which Chinese students could be assisted before leaving their home country to study abroad by their peers who are already studying in Australia. By using students mentoring from a distance and peer assisted online communication methods, the study aimed to improve transitional experiences of Chinese international students. The authors concluded that the pre-departure peer assisted online interaction provided information that eases the transition of Chinese students going to Australia. One such transitional problem that the study found is the limitation of Chinese international students in English language which their peers motivated them to learn during the pre-departure program.

Expatiating on the benefits of peer learning among graduate students in Saudi universities, Mustafa (2017) examined the extent to which peer learning is commonly used in $\mathrm{PhD}$ and Master's programs in Education. With data collected through an electronic questionnaire from a sample of 375 graduate students, the study revealed the benefits of peer learning in graduate studies in Saudi universities. The results of Mustafa's study emphasized the need for graduate students to participate in peer learning, which helps to broaden their experiences and provides them with more confidence. Participants indicated happiness with peers' comments on their graduate work and presentations which creates a positive learning environment. The researcher concluded that for the culture of peer learning to be intensively used in Saudi universities, professors should encourage, support and supervise academic discussions among students and any non-classroom activities that support the culture of peer learning.

During peer tutoring students are able to communicate on a level that they are able to understand and share with each other. Vygotsky labeled language "a powerful and strong tool" in students' interactions because of the shared meanings that form amongst students as well as the important transmission of social codes (Walmsley, Tudge, \& Winterhoff, 2003). Within the importance of language, Vygotsky recognized the importance of feedback between the students to promote a high level of joint understanding. As the students listen to and respond to each other's ideas and contributions to the interaction, they are able to reinforce their understandings, thereby extending their cognitive abilities. Feedback contributes to cognitive comprehension because of the joint understanding amongst learners learning with each other in small groups (Mustafa, 2017). Instead of defending their positions to others, when 
students listen to the explanations of their peer they are exposed to other approaches to a given task (Walmsley, Tudge, \& Winterhoff, 2003).

It is undeniable that simply listening to a teacher's presentation of complex material is not enough for most students to be able to master theoretical concepts; many students need other ways to learn theoretical concepts but more often they need "active practice in using these ideas" and theories (Cohen, 1994) in order to develop true mastery of concepts taught in class. Moreover, many subject or specialty areas in technical education require demonstrative and collaborative group methods in teaching some of the complex concepts as it is in the case of HTTTC - Kumba.

There are many techniques used in peer learning (Miao, Henderson, \& Suple, 2017), such as collaborative and cooperative learning, peer tutoring, study group, peer mentoring, peer coaching and peer assisted learning, supervisory groups, amongst others. However, for the purpose of this study only the following peer learning techniques are going to be used: study groups and peer tutoring - learning from and with class mates.

\subsection{Context of the Case}

Technical education in Cameroon at the secondary education level has grown into a fairly medium-sized system, offering opportunities for education and training in a wide variety of trades and disciplines at certificate and diploma levels in secondary schools located throughout the country. Even though the system boasts of many secondary technical schools, at the higher level there are very few technical institutions of higher learning that trains teachers for secondary technical education. There are four such higher technical teachers' training colleges with the same mission of training teachers for secondary technical education: ENSET Douala, HTTTC - Bambili, the newly created HTTTC - Kumba and ENSET Ebolowa which is yet to start. The Higher Technical Teachers` Training College of the University of Buea in Kumba (HTTTC - Kumba) was created by Presidential Decree No. 2014/090 of March 7 2014, with location in Kumba, Meme Division, South West Region. It went operational on May 4, 2015 when the first lecture was given for the start of the academic year.

The concept of Higher Technical Teachers' Training Colleges in Cameroon is to train-the-trainers in technical education, in which graduates acquired both substantive and procedures skills. Substantive skills are skills acquired in various technical skills (trades) and specialty areas; whereas procedural skills are steps of transmitting (teaching and pedagogical skills) knowledge in an area of specialization of training methodically to trainees or learners, in perspective of preparing them for ready insertion into the job market or entrepreneurship. Therefore, upon graduating from the Higher Technical Teachers' Training Colleges, the graduands are integrated into the Cameroon public service as teachers of secondary technical education of their various specialties in industrial or tertiary options.

\section{Method}

This study adopted the descriptive survey research design which involved the collection, analysis and interpretation of data from a sample of the population with the aim of generalizing findings to the other higher technical teachers' training colleges in Cameroon.

\subsection{Target Population}

The target population of the study was made up of the first batch students of cycles I and II of the different departments of HTTTC, Kumba. Table 1 shows the distribution of students in the target population according to departments and cycles, and sample representatives from each department. Participants in the study included 234 students from HTTTC, Kumba, out of a total student population of 770 which constituted the first batch of students admitted in 2015.

\subsection{Sampling Procedure}

The sample participants were selected through a simple random sampling technique in general classes in order to get representatives from all 14 departments in both cycle I and II. It is worth noting that some departments such as: Agriculture, Guidance Counseling, Law, Science of Education train student-teachers only at the higher level known as Cycle II; while the Department of Renewable Energy trains students only at the lower level known as Cycle I. The Second Cycle (Cycle II) admits candidates with bachelor's degrees and the length of time for training is two years; whereas the First Cycle (Cycle I) admits candidates with high school certificates (A/Levels, Baccalaureat) and the length of time for training is three years.

\subsection{Procedure for Data Collection}

A questionnaire containing items on the impact of study groups and the impact of peer tutoring strategies on students' success at HTTTC, Kumba was developed for the study. The questionnaire was divided into three sections covering the constructs of studying in groups, peer tutoring (learning with each other), and a section on demographic 
characteristics. Section one of the questionnaire contained five items to assess the impact of study groups on students' achievement and section two also had five items designed to determine the influence of peer tutoring on students' achievement at HTTTC, Kumba. The demographic section was made up of four items to elicit age, gender, teaching experience, and level (Cycle I or Cycle II) of participants.

As a simple way to describe opinions and suggest frequencies of respondents, response options were made up of a four point likert scales as follows : $4=$ strongly agree, $3=$ agree, $2=$ disagree, and $1=$ strongly disagree. To check for reliability and clarity, the questionnaire was pilot tested with participants of a department before administering it to other participants. After obtaining institutional permission, participants' informed consent was sought for voluntary participation in the study and ethical considerations were explained such as ensuring confidentiality of participants' responses and protection of their identity, the right to withdraw from participating, and institutional well-being.

Table 1. Departments at HTTTC - Kumba of the University of Buea

\begin{tabular}{|c|c|c|c|c|c|c|c|}
\hline & \multicolumn{2}{|l|}{ DEPARTMENTS } & Cycle I & Cycle II & TOTAL & $\begin{array}{l}\text { Sample } \\
\text { Size }\end{array}$ & $\%$ \\
\hline 1 & \multicolumn{2}{|l|}{ Administrative Techniques } & 53 & 56 & 109 & 28 & $11.8 \%$ \\
\hline 2 & \multicolumn{2}{|l|}{ Agriculture } & I & 34 & 34 & 6 & $3.1 \%$ \\
\hline 3 & \multicolumn{2}{|c|}{ Civil Engineering and Forestry Techniques } & 31 & 28 & 59 & 14 & $7.2 \%$ \\
\hline 4 & \multicolumn{2}{|l|}{ Computer Sciences } & 36 & 32 & 68 & 16 & $8.2 \%$ \\
\hline 5 & \multicolumn{2}{|l|}{ Electrical and Power Engineering } & 36 & 27 & 63 & 21 & $8.7 \%$ \\
\hline 6 & \multicolumn{2}{|l|}{ Guidance and Counseling } & / & 33 & 33 & 7 & $5.6 \%$ \\
\hline 7 & \multicolumn{2}{|l|}{ Law } & / & 40 & 40 & 11 & $5.6 \%$ \\
\hline 8 & \multicolumn{2}{|l|}{ Management Sciences } & 33 & 46 & 81 & 24 & $10.3 \%$ \\
\hline 9 & \multicolumn{2}{|l|}{ Mechanical Engineering } & 32 & 11 & 43 & 13 & $6.7 \%$ \\
\hline 10 & \multicolumn{2}{|l|}{ Renewable Energy } & 18 & l & 18 & 5 & $4.6 \%$ \\
\hline 11 & \multicolumn{2}{|l|}{ Science of Education } & l & 32 & 32 & 12 & $4.1 \%$ \\
\hline 12 & \multicolumn{7}{|l|}{ Management } \\
\hline 13 & \multicolumn{7}{|l|}{ Management } \\
\hline 14 & \multicolumn{2}{|c|}{ Tourism and Hospitality Management } & 36 & 46 & 82 & 20 & 10.3 \\
\hline & \multicolumn{2}{|l|}{ TOTAL } & 342 & 428 & 770 & 235 & $100 \%$ \\
\hline
\end{tabular}

The researcher visited each department to seek voluntary participants for the study. The purpose of the study was explained to participants and with the help of departmental delegates, participants were given copies of the questionnaire to fill-out and return to their class delegates. The administration of the questionnaire took about two weeks, including two reminders during general classes.

\subsection{Data Analysis}

The characteristics of respondents were analyzed using frequency and percentage whereas the quantitative data was analyzed using percentages scores with frequencies. The scores of each item was statistically organized and imported into SPSS V.20.0 to obtain sum, frequencies value and percentages. The percentage scores were used to interpret data gathered. The following decision rule guides the responses of each of the five items on sections one and two: A percentage range of 0 to 49 meant that the respondents generally "DISAGREE", and between 50 and 100 meant "AGREE".

\subsection{Characteristics of Study Participant}

The researcher worked with a sample of 235 students selected from 14 departments of HTTTC, Kumba. A total of 235 questionnaires were distributed and 234 were collected from the participants who were made up of students of both Cycle I and Cycle II from all 14 departments. Table 2 provides a summary of the demographic characteristics of the participants. The demographic data included gender, age, teaching experience, and level. As shown on Table 2, a total of 234 students responded to the questionnaire, with 144 (61.5\%) being males, and 90 (38.5\%) females. Age 
groups of respondents ranged between 15 to 19 years (7.7\%), 20 to 25 years old (39.7\%), 26 to 30 years old (41.5\%), and 30 years and above (7.7\%). More respondents $127(54.3 \%)$ had no teaching experience before entering into HTTTC, Kumba, while $97(41.5 \%)$ of the participants had some teaching experience before gaining admission into HTTTC, Kumba.

Table 2. Demographics of Study Participants

\begin{tabular}{|c|c|c|c|c|c|}
\hline \multirow{2}{*}{$\begin{array}{l}\text { ITEM } \\
\text { CYCLE }\end{array}$} & \multicolumn{4}{|c|}{ RESPONDENTS } & \multirow[t]{2}{*}{ TOTAL } \\
\hline & \multicolumn{2}{|l|}{ CYCLE I } & \multicolumn{2}{|l|}{ CYCLEII } & \\
\hline & \multicolumn{2}{|l|}{115} & \multicolumn{2}{|l|}{119} & 234 \\
\hline & \multicolumn{2}{|l|}{$46.7 \%$} & \multicolumn{2}{|l|}{$53.3 \%$} & $100 \%$ \\
\hline \multirow[t]{3}{*}{ GENDER } & \multicolumn{2}{|l|}{ MALE } & \multicolumn{2}{|l|}{ FEMALE } & \\
\hline & \multicolumn{2}{|l|}{144} & \multicolumn{2}{|l|}{90} & 234 \\
\hline & \multicolumn{2}{|l|}{$61.5 \%$} & \multicolumn{2}{|l|}{$38.5 \%$} & $100 \%$ \\
\hline \multirow[t]{3}{*}{ AGE } & $(15-19)$ & $(20-25)$ & $(26-30)$ & $(30+)$ & \\
\hline & 18 & 93 & 97 & 26 & 234 \\
\hline & $7.7 \%$ & $39.7 \%$ & $41.5 \%$ & $11.1 \%$ & $100 \%$ \\
\hline \multirow{3}{*}{$\begin{array}{l}\text { TEACHING } \\
\text { EXPERIENCE }\end{array}$} & \multicolumn{2}{|l|}{ YES } & \multicolumn{3}{|l|}{ NO } \\
\hline & \multicolumn{2}{|l|}{97} & \multicolumn{2}{|l|}{127} & 224 \\
\hline & \multicolumn{2}{|l|}{$41.5 \%$} & \multicolumn{2}{|l|}{$54.3 \%$} & $95.8 \%$ \\
\hline
\end{tabular}

\section{FINDINGS}

\subsection{The Effect of Study Groups on Students' Achievement in HTTTC, Kumba}

To determine the impact of study groups on students' achievement at HTTTC, Kumba, five items were designed with response options for respondents to choose according to their experiences studying in groups with classmates. When asked if learning with course mates give them confidence that they will pass the course, as indicated on Table 3 , the majority of students who participated in the study (that is $20.5 \%$ and $57.5 \%$ ) strongly agreed and agreed that when the teacher groups them in small groups in class they get the confidence that they are going to perform better in the course, whereas $17.1 \%$ disagreed and $4.7 \%$ strongly disagreed. For example, there was a total of 11 and 40 respondents who strongly disagreed and disagreed $(4.7 \%$ and $17.1 \%$ ) respectively while a total of 48 and 135 strongly agreed and agreed respectively scoring a percentage of $(20.5 \%$ and $57.5 \%)$. The decision for item one is AGREE since the overall percentage for "AGREE" (78\%) is higher than the overall percentage score for "DISAGREE" - $21.8 \%$. 
Table 3. Respondents Views on Study Groups Effect on Students' Achievement

\begin{tabular}{|c|c|c|c|c|c|}
\hline $\begin{array}{l}\text { Study Groups and students } \\
\text { achievement }\end{array}$ & $\begin{array}{l}\text { Strongly } \\
\text { Disagree }\end{array}$ & Disagree & Agree & $\begin{array}{l}\text { Strongly } \\
\text { Agree }\end{array}$ & Decision \\
\hline & $\mathbf{N}^{*}(\%)$ & $\mathbf{N}^{*}(\%)$ & $\mathbf{N}^{*}(\%)$ & $\mathbf{N *}(\%)$ & \\
\hline $\begin{array}{l}\text { Learning with my course } \\
\text { mates give me confidence that } \\
\text { I would pass my courses }\end{array}$ & $\begin{array}{l}11 \\
(4.7 \%)\end{array}$ & $\begin{array}{l}40 \\
(17.1 \%)\end{array}$ & $\begin{array}{l}135 \\
(57.5 \%)\end{array}$ & $\begin{array}{l}48 \\
(20.5 \%)\end{array}$ & \\
\hline TOTAL & $(21.8 \%)$ & & $(78 \%)$ & & AGREE \\
\hline $\begin{array}{l}\text { Learning with course mates } \\
\text { give me confidence in my } \\
\text { ability to pass my final } \\
\text { examination }\end{array}$ & $\begin{array}{l}8 \\
(3.4 \%)\end{array}$ & $\begin{array}{l}41 \\
(17.5 \%)\end{array}$ & $\begin{array}{l}147 \\
(62.8 \%)\end{array}$ & $\begin{array}{l}38 \\
(16.2 \%)\end{array}$ & \\
\hline TOTAL & $(21 \%)$ & & $(79 \%)$ & & AGREE \\
\hline $\begin{array}{l}\text { Work with my class mates } \\
\text { gives me assurance that I will } \\
\text { complete my work on time. }\end{array}$ & $\begin{array}{l}22 \\
(9.5 \%)\end{array}$ & $\begin{array}{l}37 \\
(15.8 \%)\end{array}$ & $\begin{array}{l}113 \\
(48.3 \%)\end{array}$ & $\begin{array}{l}60 \\
(25.6 \%)\end{array}$ & \\
\hline TOTAL & $(25.3 \%)$ & & $(73.9 \%)$ & & AGREE \\
\hline $\begin{array}{l}\text { Working with class mates } \\
\text { enable me develop team spirit }\end{array}$ & $\begin{array}{l}4 \\
(1.7 \%)\end{array}$ & $\begin{array}{l}9 \\
(3.8 \%)\end{array}$ & $\begin{array}{l}83 \\
(35.5 \%)\end{array}$ & $\begin{array}{l}137 \\
(58.5 \%)\end{array}$ & \\
\hline TOTAL & $(5.5 \%)$ & & $(94 \%)$ & & AGREE \\
\hline $\begin{array}{l}\text { Doing assignments in groups } \\
\text { encourage me to learn better }\end{array}$ & $\begin{array}{l}8 \\
(3.4 \%)\end{array}$ & $\begin{array}{l}10 \\
(4.3 \%)\end{array}$ & $\begin{array}{l}109 \\
(46.6 \%)\end{array}$ & $\begin{array}{l}107 \\
(45.7 \%)\end{array}$ & \\
\hline TOTAL & $(7.7 \%)$ & & $(92.3 \%)$ & & AGREE \\
\hline \multicolumn{3}{|l|}{ OVERALL DECISION SCORE: } & $83.44 \%$ & & AGREE \\
\hline
\end{tabular}

*Total number of participants responding to each item

Item two asked respondents to indicate their opinions on whether learning with other students who take the same courses gave them confidence and ability to pass their final examination. Based on the occurrences of the responses for the item, 147 of the participants generally agreed (agree 62.8\%, and strongly agreed 16.2\%) giving an overall positive rating (AGREE - 79\%) that they perform better in their final exam when they work with other students taking the same courses; whereas $41(17.5 \%)$ and $8(3.4 \%)$ disagree and strongly disagree respectively, giving a negative rating of $21 \%$.

When asked whether studying together with their classmates gives them assurances that they will complete their training on time in item three, many respondents $113(48.3 \%)$ and $60(25.6 \%)$ agreed and strongly agreed with the statement; whereas some respondents $37(15.8 \%)$ and $22(9.5 \%)$ disagreed and strongly disagreed that they will complete their work on time when they work with peers. The rating for this item is AGREE with $73.9 \%$ positive and $25.3 \%$ negative.

Participants were also asked to indicate whether studying in groups with classmates brings about team spirit in item four. A large majority of the participants $137(58.5 \%)$ and $83(35.5 \%)$ strongly agreed and agreed with the statement, whereas very few participants $4(1.7 \%)$ and $9(3.8 \%)$ strongly disagreed and disagreed that working with classmates enabled them to develop team spirit. The decision for this statement is AGREE; 94\% positive and 5.5\% negative. The last item to elicit the effects of study groups on students' achievement asked participants whether doing their assignments in groups with classmates encouraged them to learn better. As shown on the table above, 107 (45.7\%) and $109(46.6 \%)$ of study participants strongly agreed and agreed with the statement. Only $10(4.3 \%)$ and $8(3.4 \%)$ respondents disagreed and strongly disagreed that doing assignments in groups encouraged them to learn better with a $92.3 \%$ AGREE positive rating. 
The general results show that responses of all five items indicated that a majority of respondents strongly agreed and agreed that learning with their classmates and course mates gives them confidence that they would pass their courses and the ability to pass their final examinations; they also strongly generally agreed that working with their classmates gives them assurance that they will complete their training on time, it enables them to develop team spirit, and encourages them to learn better. The percentages of strongly agreed and agreed response choices of participants were computed to an overall decision score to determine the impact of study group on students' achievement at HTTTC, Kumba and it was $83.44 \%$ - AGREE . Therefore, from the agreement rating, many respondents agreed that studying in groups with their classmates enabled them to pass their courses and to complete their training program on time for integration into the public service to serve as teachers.

\subsection{Effects of Peer Tutoring on Students' Achievement at HTTTC, Kumba}

The next set of items on Table 4 was designed to determine the impact of peer tutoring on students' achievements in HTTTC, Kumba. Five items were developed to elicit respondents' responses on one-to-one tutoring by a classmate or learning with a classmate or another student in the same course(s). Table 4 shows the results in frequencies and percentages of options chosen by respondents on the effect of peer tutoring on students' achievements at HTTTC, Kumba. These response options were the same as in the study group construct. The percentage for the two positive options (strongly agreed and agreed) were merged to give an "AGREE Decision", while that of the two negative options (strongly disagree and disagree) were merged to give a "DISAGREE Decision" and an overall decision score was calculated at the end of the table.

Table 4. Respondent Views on Peer Tutoring Effect on Students' Achievement

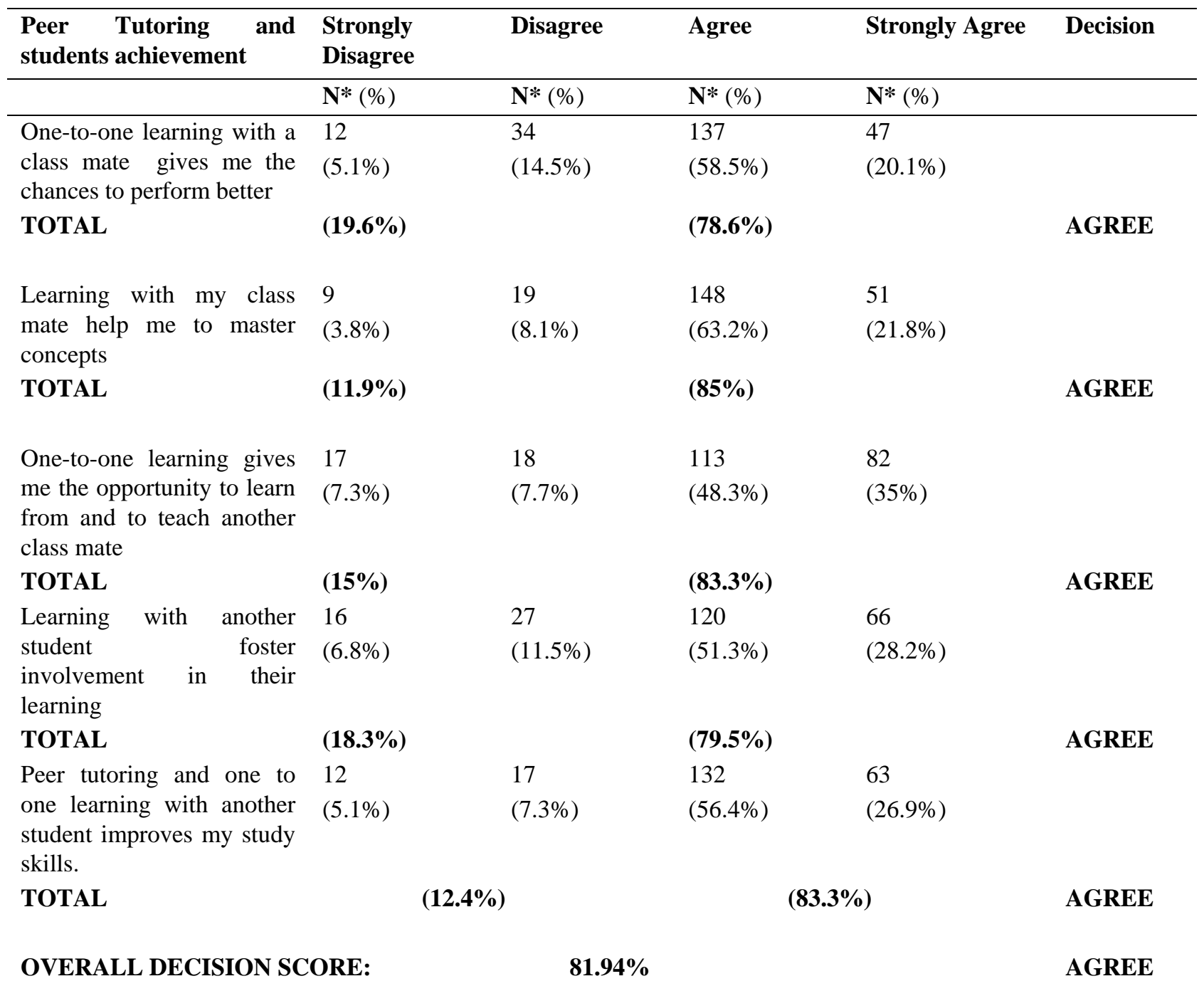

*Total number of participants responding to each item. 
To examine the impact of peer-tutoring on students' academic achievements at HTTTC, Kumba, participants were asked if one-to-one learning with a classmate gives them the chance to perform better. Many participants agreed $(58.5 \%)$ and strongly agreed $(20.1 \%)$ that one-to-one learning with a classmate helps them to perform better, whereas $14.5 \%$ disagreed and $5.1 \%$ are strongly disagreed. The decision for item one is AGREE since the overall positive percentage rating for the item is $78.6 \%$. Similarly in item two, participants were asked to indicate if learning with a classmate helps them to master concepts taught in class. Majority of participants $63.2 \%$ and $21.8 \%$ agreed and strongly agreed respectively that learning with a classmate helps them to better understand concepts taught in class, giving an overall positive rating decision of $85 \%$ - AGREE; whereas $8.1 \%$ and $3.8 \%$ of the participants disagreed and strongly disagreed with the statement. The next item was to elicit participants' opinions whether or not one-to-one learning gives them the opportunity to learn from and to teach another classmate. More participants $48.3 \%$ and 35\% agreed and strongly agreed that one-to-one learning gives them opportunity to learn from a classmate and also teach a classmate, while $7.7 \%$ and $7.3 \%$ of participants disagreed and strongly disagreed with the statement. The decision rating for this item is AGREE with $83.3 \%$ positive and $15 \%$ negative.

To elicit whether peer tutoring enhanced students' involvement in their own learning, participants were asked to indicate if learning with another student foster students' involvement in their own learning. As indicated by participants' responses, $51.3 \%$ and $28.2 \%$ agreed and strongly agreed that learning with other students foster students' involvement in their own learning, while $11.5 \%$ disagreed and $6.8 \%$ strongly disagreed. The rating for this item is AGREE with $79.5 \%$ positive and $18.3 \%$ negative. The last item for this section linked the concepts of peer tutoring and one-to-one tutoring by another student for participants to indicate if the two concepts improve their study. As indicated on Table 4, many participants $56.4 \%$ and $26.9 \%$ agreed and strongly agreed respectively that peer tutoring and one-to-one tutoring by another student improves their study skills, while $7.3 \%$ disagreed and $5.1 \%$ strongly disagreed. The rating for this last item is AGREE with $83.3 \%$ positive and $12.4 \%$ negative. An overall decision score of 81.9 was obtained as an AGREE rating for effects of peer tutoring on students' achievement at HTTTC, Kumba.

\section{Discussion}

The importance of peer learning in student skills and cognitive development cannot be overlooked. The overall decision scores of the impact of study groups' effect on students' achievement and peer tutoring effect on students' achievement for this study are $83.44 \%$ and $81.94 \%$ respectively. The findings of this study justify the literature reviewed on the pedagogical benefits of peer learning and peer tutoring amongst college students. Similar to other studies (Gillies, 2004; LaFleur, 2010; Amaka, 2013; Comfort \& McMahon, 2014; Garcia, Morales, \& Rivera, 2014; Campit, Cayabyab, \& Galas, 2015; Mustafa, 2017; Miao, Henderson, \& Supple, 2017), the findings indicated that students learning with class mates and with others taking the same courses performed better than those that are not exposed to peer learning and peer tutoring. As indicated by the findings of this study, when the teaching-learning process is done in a simple and practical way as provided by peer tutoring, students are more interested in their study and therefore the chances for them to perform better in the training are higher.

Study groups are important strategy of learning that can surely help students when they are overloaded with assignments and when they have too many materials to master. This is in line with the study conducted by Ling (2015), which indicated that group study was preferable since it enables the learner to go through much material within a limited time frame, minimizes examination stress and anxiety, and provide students with the chance to perform well during examinations.

The findings of this study also revealed that apart from academic performance peer learning can enable students to develop positive interpersonal relationship with peers and acquire self-confidence which is an important characteristic of a good teacher. This is what Lafleur (2010) confirms in his study entitled "peer learning and student's confidence", which concluded that peer learning helps students' to exhibit confidence and enhance their communication skills.

\section{Conclusion and Recommendations}

Peer learning provides tools to educators to incorporate values in providing quality education. To achieve the full benefits of this tool, the teacher should be in tune with the learning needs of students. There is ample evidence to show the need and effectiveness of peer learning not only in classrooms but in training programs. It is very important to implement peer learning properly to attain maximum benefits. Educators can use their understanding of peer learning and utilize this tool effectively in the classroom to motivate students to learn with and tutor each other.

Peer learning represents a key component of the cultures of learning among students of the Higher Technical Teachers' Training College, Kumba. Based on the key findings of this study, it can be recommended that student(s) 
who are more knowledgeable and have a good mastery of the subject and concepts be either placed in small groups by the teacher for group assignments and learning discussions in a more structure way. Teachers should also take advantage of the peer tutoring technique to make students work in small mixed ability and diverse groups that will allow every student whether fast or slow to share their ideas and build knowledge as well as interpersonal skills in the process. Teachers will also need to instruct peer tutors to ensure that they possess the requisite academic and tutoring skills. Therefore, there is need for more teacher supervisory groups during the peer learning process.

Peer learning builds on students' strengths and mobilizes them as active participants in the learning process thereby, enhancing student self esteem and achievement. For instance, some students during group study activities are very confident to take the lead amongst their peers whereas they were very shy to speak in class. This type of student behavior is very common among students at HTTTC, Kumba. Therefore, as educators are continuously in search for diverse learning techniques to improve students' achievement, peer learning can be suggested as one of the learning techniques for teachers' further exploit in an attempt to provide a conducive learning environment for students with different educational, cultural, and linguistics backgrounds. Variety of peer learning strategies are available to teachers to enables each individual teacher to thoroughly research the structure and advantages of each peer learning technique before implementing in his or her classes.

\section{References}

Andrews, M. \& Manning, N. (2015). Peer learning in public sector reforms. Paris: Effective Institutions Platform (EIP).

Amaka, O. A. (2013). Effects of peer tutoring methods on students academic achievement in Home Economics. Academic Journal of Interdisciplinary Studies, 2(5), 193-197. https://doi.org/10.5901/ajis.2013.v2n5p193

Ayuba, R. \& Walker, S., (2011). Cooperative Learning Effects on the Classroom. Michigan, Northern Michigan State University.

Bernero, J. (2000). Motivating students in math using cooperative learning. (ERIC Document reproduction service No.ED446 999).

Brown, J. S., Collins, A., \& Duguid, P. (1989). Situated cognition and the culture of learning. Educational Researcher, 18(1), 32-42. https://doi.org/10.3102/0013189X018001032

Campit, J. B., Cayabyab, J., \& Galas, E. (2015). The effect of peer tutoring on achievement of students in discrete structures. Asia Journal of Multidisciplinary Research, 3(5), 8-12.

Chen, C., \& Liu, C. C. (2011). A case study of peer tutoring program in higher education. Research in Higher Education Journal, 11, 1-10.

Comfort, P., \& McMahon, J. J. (2014). The effect of peer tutoring on academic achievement. Journal of Applied Research in Higher Education, 6(1), 168-175. https://doi.org/10.1108/JARHE-06-2012-0017

Cohen, E. G. (1994). Restructuring the classroom: Conditions for productive small group. Review of Education Research, 64(1), 25-34. https://doi.org/10.3102/00346543064001001

Dunn, R. (2001). Practical approaches to teaching young adults to teach themselves. Swedish Jönköping: Brain Books.

Felder, B. \& Brent, F., (2007). Cooperative learning. Journal of Education and Learning. 9(3), 246-255. https://doi.org/10.1021/bk-2007-0970.ch004

Garcia, R., Morales, J. C., \& Rivera, G. (2014). The use of peer tutoring to improve the passing rates in mathematics placement exams of engineering students: A success story. American Journal of Engineering Education, 5(2), 61-72. https://doi.org/10.19030/ajee.v5i2.8952

Gillies, R. M. (2004). The effects of cooperative learning on junior high school students during small group learning. Learning and Instruction, 14(2), 197-213. https://doi.org/10.1016/S0959-4752(03)00068-9

Gillies, R. (2006). Teachers' and students' verbal behaviours during cooperative and small-group learning. British Journal of Educational Psychology, 76, 271-287. https://doi.org/10.1348/000709905X52337

Gillies, R. (2008). The effects of cooperative learning on junior high school students' behaviours, discourse, and learning during a science-based learning activity. School Psychology International, 29, 328-347. https://doi.org/10.1177/0143034308093673

Gillies, R. M. (2016). Cooperative Learning: Review of Research and Practice. Australian Journal of Teacher 
Education, 41(3), 39-54. https://doi.org/10.14221/ajte.2016v41n3.3

Goodlad, J. (1984). A place called school: Prospects for the future. New York: McGraw-Hill Books Co., New York.

Harman, G., \& Nguyen, T. N. (2010). Reforming teaching in Vietnam's higher education system. In G. Haaland, M. Hayden, \& T. Nghi (Eds.), Reforming Higher Education in Vietnam: Challenges and Priorities (pp. 65-86). London: Springer. https://doi.org/10.1007/978-90-481-3694-0

Jackson, C. K., \& Bruegmann, E. (2009). Teaching students and teaching each other: The importance of peer learning for teachers. Retrieved [2018], from Cornell University, School of Industrial and Labor Relations site: http://digitalcommons.ilr.cornell.edu/workingpapers/77/ https://doi.org/10.3386/w15202

Johnson, D.W., \& Johnson, R.T. (1991). Learning together and alone: Cooperative, competitive, and individualistic. ( $3^{\text {rd }}$ Ed.). Englewood Cliffs, NJ: Prentice Hall.

Johnson, D.W., Johnson, R.T., Holubec, E.J., \& Roy, P. (1984). Circles of learning: Cooperation in the classroom. Alexandria, VA: Association for Supervision and Curriculum Development.

LaFleur, P. (2010). Peer tutoring: Student achievement, confidence and the teacher's role Partnership Action Research Project Report.

Ling, X. (2015). Application of cooperative learning approach: teachers' and students' perceptions towards cooperative learning. Master of Science of Education in Teaching English to Speakers of Other Languages (TESOL), Department of Language, Learning and Leadership: State University of New York, Fredonia, New York.

Magin, D. J., \& Churches, A. E. (1995). Peer tutoring in engineering design: A case study. Studies in Higher Education, 20(1), 73-85. https://doi.org/10.1080/03075079512331381810

Miao, L., Henderson, F., \& Supple, B. (2017). Online pre-departure peer learning: What are the transition benefits for Chinese students? Journal of Peer Learning, 10, 1-17.

Mustafa, G.M.M. (2017). Learning with Each Other: Peer Learning as an Academic Culture among Graduate Students in Education. American Journal of Educational Research, 5(9), 944-951.

Power, C., \& Dunphy, K. (2010). Peer facilitated learning in Mathematics for Engineering: A case study from an Australian university. Engineering Education, 5(1), 75-84. https://doi.org/10.11120/ened.2010.05010075

Oneneto, L.U. \& Onyibor, M. (2002). Concept mapping system of instruction: An alternative education delivery system in economics in Mvogbo. J.O. National Policy on Education for Sustainable Development Issues for 21st Century, Faculty of Education, Enugu State University of Science and Technology (ESUT), Nigeria.

Ranjani, B. I. (2013). Relationship between cooperative learning and student achievement. International Journal of Education and Information Studies, 3(1), 21-25.

Tella, A. (2013). The effect of peer tutoring and explicit instructional strategies on primary school pupils learning outcomes in mathematics. Bulgarian Journal of Science and Education Policy, 7(1), 5-25.

Titanji, P. F. (2013). 50 years of education reforms in Cameroon. In D. A. Tchoyi \& S. C. M'Bafou (Eds.), 50 ans de reforme de l'etat au Cameroun: Strategies, bilans et perspectives. L'Harmattan, Yaounde, Cameroon.

Walmsley, A. L., Tudge, E. \& Winterhoff, (2003). Cooperative learning and its effects in a high school geometry classroom. Mathematics Teacher Education, 96(2), 112-116.

Yager, R. E. (2000). The constructivist learning model. The Science Teacher, 67(1), 44-45.

Yamarik, S. (2007). Does cooperative learning improve student learning outcomes? Journal of Economic Education, 38(3), 259-277. https://doi.org/10.3200/JECE.38.3.259-277 